\title{
A TUTELA COLETIVA COMO INSTRUMENTO DE ACESSO À JUSTIÇA
}

\author{
COLLECTIVE PROTECTION AS A TOOL \\ FOR ACCESS TO JUSTICE
}

Octaviano Langer ${ }^{1}$

\begin{abstract}
RESUMO: O presente artigo relata os resultados de pesquisa que correlacionou os institutos da Tutela Coletiva e do Acesso à Justiça. Percebeu-se a Tutela Coletiva como um exercício jurisdicional diferenciado, no qual seus quatro elementos, litígio, processo, partes e juiz, carecem de uma nova roupagem para a devida garantia dos interesses da coletividade. O Acesso à Justiça é visto sob uma perspectiva material, como um sistema acessível a todos e que produza resultados socialmente justos. E o processo coletivo, considerando a importância do bem jurídico nele tutelado, é compreendido como uma ferramenta destacada para a garantia dos Direitos Fundamentais Coletivos.
\end{abstract}

Palavras Chave: Tutela coletiva; Jurisdição; Acesso à justiça.

\begin{abstract}
This article reports the results of research that correlated the Institutes of Public Guardianship and the Access to Justice. Realized the Public Guardianship Office as a distinguished court, where his four elements, litigation, proceedings, parties and courts, need a new dress for the proper promotion of the interests of the community. The Access to Justice is viewed from a perspective of material, such as a system accessible to all and which produce socially equitable outcomes. And the collective process, considering the importance of the legal ward it is understood as a tool deployed for the security of Fundamental Rights Collective.
\end{abstract}

Keywords: Public guardianship; Jurisdiction; Access to justice.

\section{INTRODUÇÃO}

Este artigo é fruto de investigação realizada na área da atuação jurisdicional quando do trato dos Direitos Fundamentais Coletivos. Para tanto, parte-se do reconhecimento de que o Poder Judiciário passa por uma crise momentânea de inadequação funcional, especialmente relacionada com a dificuldade de se proporcionar uma maior efetividade aos processos coletivos. Seja por falta de legislação específica, seja por falta de compreensão do potencial da tutela coletiva, o que se percebe é a dificuldade de se obter resultados socialmente justos a partir da atuação jurisdicional.

\footnotetext{
${ }^{1}$ Aluno Regular do Curso de Mestrado em Ciência Jurídica da Universidade do Vale do Itajaí - UNIVALI. Especialista em Direito Processual pela Universidade do Extremo Sul Catarinense - UNESC. E-mail: octavianolanger@hotmail.com
} 
Tem-se como pano de fundo desta discussão o papel do Judiciário em um Estado Democrático de Direito marcado por inércias executivas e legislativas na realização de políticas públicas, voltadas para a consecução de direitos coletivos constitucionalmente previstos. Sobressai daí a atuação jurisdicional, que é chamada para resolver conflitos com alto teor de conflituosidade e natureza política.

Propõe-se então, a fim de contribuir com este debate, que uma interpretação diferenciada dos institutos relacionados com a tutela coletiva pode auxiliar na produção de resultados judiciais que maximizem a concretização de direitos voltados para o bem comum e desenvolvimento social. Ademais, identifica-se a tutela coletiva como importante ferramenta de acesso à justiça de todos aqueles que serão beneficiados pela atuação judicial, bem como o processo coletivo como instrumento democrático para a realização de direitos.

Utilizou-se o método indutivo na fase de investigação, o método cartesiano na fase de tratamento dos dados recolhidos, e os resultados são apresentados sob o método indutivo, sendo operadas as técnicas do referente, da categoria, do conceito operacional e da pesquisa bibliográfica (PASOLD, 2007, p. 25-74, 81-105).

\section{A TUTELA COLETIVA DE DIREITOS}

A busca de uma compreensão da tutela coletiva de direitos passa necessariamente pelo entendimento da atividade jurisdicional do Estado, voltada para o equacionamento dos conflitos envolvendo direitos ou interesses coletivos em sentido amplo (LEONEL, 2002, p. 17). Tomando como ponto de partida um conceito de jurisdição e a definição de seus elementos básicos, é possível construir-se a idéia de tutela coletiva justamente a partir da diferenciação de tais elementos, que recebem uma nova roupagem quando destinados à guarda dos direitos da coletividade. Traz-se, então, de Niceto Alcalá-Zamora Y Castilho (1974, p. 57-58) o conceito e os elementos da Jurisdição. Para este autor, jurisdição é a:

Função desenvolvida pelo Estado para conhecer, decidir, e se necessário executar as sentenças proferidas com caráter imperativo por um terceiro imparcial, instituído pelo próprio Estado e situado acima das partes, acerca de uma ou mais pretensões litigiosas deduzidas pelas partes, e trazidas ao julgador pelo correspondente processo.

E ainda de acordo com Alcalá-Zamora Y Castilho (1974, p. 57-58), a jurisdição aparece como a soma de quatro elementos: "dois subjetivos - as partes que pedem e o juiz que de- 
cide; e dois objetivos - $\underline{\text { o litígio, }}$ que reflete as pretensões deduzidas pelas partes, e o processo, que serve para encaminhar tais pretensões até a decisão final."

Destarte, na seara coletiva, o que se percebe é um exercício jurisdicional diferenciado, em que os elementos que a compõem assumem feições próprias, destinadas a tutela de interesses e direitos transindividuais.

Sob o viés do direito coletivo, tem-se um litígio baseado em um direito ou interesse coletivo em sentido amplo, que é trazido ao judiciário mediante o competente processo, que deve ser entendimento como um instrumento garantidor da melhor prestação jurisdicional aplicável ao caso.

Tal processo deve ser proposto por um representante adequado, capaz de patrocinar a causa com a máxima eficiência postulatória e instrutória, e ser conduzido por um juiz que se apresente como um agente comprometido com os ideais do Estado Democrático de Direito, e consciente da importância de sua decisão para a garantia dos interesses da coletividade.

Desta forma, na tutela coletiva cada elemento da jurisdição deve receber uma conotação diferenciada, justamente para propiciar uma melhor tutela destinada à proteção dos direitos coletivos em sentido lato, potencializando os instrumentos processuais destinados à defesa dos interesses difusos e coletivos.

A seguir, os elementos da jurisdição revisitados sob a ótica da tutela coletiva, iniciando-se, para fins didáticos, pelos elementos objetivos:

\section{O LITÍGIO}

O litígio na tutela coletiva tem como objeto direitos ou interesses transindividuais (também chamados de coletivos em sentido amplo), os quais são compartilhados por grupos, classes ou categorias de pessoas. São direitos que excedem o âmbito individual, e que envolvem grupos determináveis ou indetermináveis de pessoas.

Cabe ressaltar a existência de diversos dispositivos constitucionais que tratam de direitos coletivos, como a defesa do consumidor ${ }^{2}$ e do meio ambiente ${ }^{3}$, além de instrumentos inéditos criados pelo constituinte de 1988, como o mandado de injunção, o mandado de segurança coletivo e o habeas data ${ }^{4}$, que chamam a atenção para a importância da tutela dos direitos da coletividade.

\footnotetext{
${ }^{2} \mathrm{CF} / 88$, art. $5^{\circ}$. O Estado promoverá, na forma da lei, a defesa do consumidor.

${ }^{3} \mathrm{CF} / 88$, art. 225 .

${ }^{4}$ Art. $5^{\circ}$, incs. LXX, LXXI e LXXII.
} 
Paulo Bonavides (2003) bem ressalta a tendência constitucional de 1988 no resguardo dos direitos coletivos. Tanto que, ao escrever sobre o mandado de segurança coletivo, ressalta:

A constituição manifestou com a ampliação da garantia o apreço que vota à defesa coletiva dos direitos, nomeadamente quando ocorre uma imbricação do direito subjetivo individual com o interesse não menos subjetivo do ente político, sindical ou associativo, legitimado doravante para impetrar o referido mandado (BONAVIDES, 2003, p. 255).

Contudo, tais direitos foram especialmente tratados na legislação infraconstitucional brasileira, destacando-se o Código de Defesa do Consumidor (Lei. 8.078/1990) , $^{5}$ que passou a distingui-los segundo sua origem, nomeando-os como direitos ou interesses difusos, coletivos (em sentido estrito) e individuais homogêneos.

Para melhor entendimento, segue lição de Hugo Nigro Mazzilli (2005, p. 48-49):

a) se o que une interessados determináveis, com interesses divisíveis, é a origem comum da lesão (p. ex., os consumidores que adquirem produtos fabricados em série com o mesmo defeito), temos interesses individuais homogêneos; b) se o que une interessados determináveis é a circunstância de compartilharem a mesma relação jurídica indivisível (como os consumidores que se submetem à mesma cláusula ilegal em contrato de adesão), temos interesses coletivos em sentido estrito; c) se o que une interessados indetermináveis é a mesma situação de fato, mas o dano é individualmente indivisível (p. ex., os que assistem pela televisão à mesma propaganda enganosa), temos interesses difuso.

Desta feita, o processo coletivo, diferente do processo individual, tem como causa de pedir um direito coletivo no sentido amplo, seja ele difuso, coletivo (em sentido estrito), ou individual homogêneo. Continuando nos ensinamento de Hugo Nigro Mazzilli (2005, p. 49):

\footnotetext{
$\mathrm{Na}$ tutela coletiva, estabelece-se uma controvérsia sobre interesses de grupos, classes ou categoria de pessoas (enquanto, nos conflitos coletivos, o objeto da lide são interesses difusos, coletivos ou individuais homogêneos, já, nos conflitos individuais, de regra a controvérsia cinge-se a interesses propriamente individuais.
}

Cabe, por fim, ressaltar que tais direitos ainda se encontram em evolução. As alterações recentes vividas pela sociedade civil e pelo Estado refletem diretamente no Direito. O Direito não nasce pronto e acabado, e não é imutável, devendo evoluir e acompanhar tais transformações. Citando Norberto Bobbio (2004, p. 24):

${ }_{5}^{5}$ Art. 81, da Lei 8.078/90 (CDC) 
Os direitos do homem, por mais fundamentais que sejam, são direitos históricos, ou seja, nascidos em certas circunstâncias, caracterizadas por lutas em defesa de novas liberdades contra velhos poderes, e nascidos de modo gradual, não todos de uma vez e nem de uma vez por todas.

As relações sociais modernas criaram novos "nichos" de conflituosidade, e que surgem carentes de uma tutela jurisdicional específica. Como bem diagnostica Paulo Cruz (2007, p. 163):

A percepção das conseqüências do crescimento econômico e, principalmente, do desenvolvimento industrial, sobre as condições que fazem possível a vida humana, deram lugar a uma crescente preocupação pela manutenção destas condições. Bens que eram dados como inesgotáveis em outras épocas, como a água, o ar limpo, alimentos sem conservantes e a ausência de matérias tóxicos nos ambientes vitais começam, hoje, a ocupar lugar de destaque nas preocupações de todas as sociedades.

Daí o reconhecimento de direitos que extrapolam a individualidade, e que necessitam de uma tutela diferenciada. Isto porque, o descuido com os bens destinados à coletividade deixam:

[...] em perigo o bem-estar - e a vida - não de uns poucos indivíduos, mas sim, de importantes e numerosos setores da Sociedade, quando não de toda ela. Isto explica por que, progressivamente, as Constituições e as declarações internacionais passaram a incluir a necessidade de reconhecer e impor direitos distintos daqueles classicamente declarados. Já não são direitos negativos diante do poder do Estado ou de participação política, ligados à obtenção de prestações de serviços sociais públicos. Trata-se agora de proteger bens comuns, não individualizáveis, mas que são condição essencial para a qualidade de vida de cada indivíduo. São direitos fundamentais de terceira geração (CRUZ, 2007, p. 163-164).

Paulo Bonavides (2003, p. 569) também identifica a importância destes direitos de terceira geração:

[...] com efeito, um novo pólo jurídico de alforria do homem se acrescenta historicamente aos da liberdade e da igualdade. Dotados de altíssimo teor de humanismo e universalidade, os direitos de terceira geração tendem a cristalizar-se no fim do século $\mathrm{XX}$ enquanto direitos que não se destinam especificamente à proteção dos interesses de um indivíduo, de um grupo ou de um determinado Estado. Tem primeiro por destinatário o gênero humano mesmo, num momento expressivo de sua afirmação como valor supremo em termos de existencialidade concreta [...]. Emergiram eles

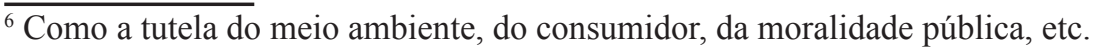


da reflexão sobre temas referentes ao desenvolvimento, à paz, ao meio ambiente, à comunicação e ao patrimônio comum da humanidade.

Assim, reconhecidamente oriundos de uma evolução histórica, os direitos de terceira geração são resultados das atuais relações sociais (mais complexas) e de um exercício mais efetivo de cidadania. Norberto Bobbio (2004, p. 26) esclarece que:

\begin{abstract}
Os direitos de terceira geração, como o de viver num ambiente não poluído, não poderiam ter sido sequer imaginados quando foram propostos os de segunda geração, do mesmo modo como estes últimos (por exemplo, o direito à instrução ou à assistência) não eram sequer concebíveis quando foram promulgadas as primeiras Declarações setecentistas.
\end{abstract}

Cabe então aos juristas pátrios um dupla batalha: a batalha pela concretização dos direitos coletivos (em sentido amplo) atualmente já positivados na legislação constitucional e infraconstitucional, e a batalha pela ampliação e criação de novos direitos que melhor amparem os interesses da coletividade.

\title{
O PROCESSO
}

Na tutela coletiva, o processo deve ser visto como um instrumento de máxima garantia dos direitos da coletividade. Mais do que uma série de ritos, na seara coletiva o processo se destina à concretização de interesses transindividuais. Seguindo o pensamento de José Miguel Garcia Medina (2007, p. 623-624):

\footnotetext{
Os direitos tutelados pela via das ações coletivas necessitam de uma tutela jurisdicional executiva de resultados efetivos. [...] A decisão judicial proferida em uma ação coletiva nem sempre, por si só, implicará em solução suficiente para o conflito submetido ao exame do Poder Judiciário; este também deverá ter condições de forçar a observação do Direito.
}

O processo coletivo é, desse modo, marcado por um fim. A importância do direito tutelado deve servir como legitimação para que o processo se apresente como um instrumento efetivo de tutela dos direitos coletivos. Trata-se de um verdadeiro recurso destinado à busca de soluções para problemas que envolvem a sociedade. 
Willis Santiago Guerra Filho (2001) reconhece a importância da esfera coletiva, ao comentar que a tutela dos interesses de grupos apresenta-se como um dos traços característicos desta época (pós-modernidade), "quando então as ações mais significativas se deveriam a esses novos sujeitos coletivos, e não mais a sujeitos individuais ou àqueles integrados na organização política estatal" (GUERRA FILHO, 2001, p. 25). E ressalta a importância do processo como um meio de participação política, ao considerar que "o processo judicial que se instaura mediante a propositura de determinadas ações, especialmente aquelas de natureza coletiva e/ou de dimensão constitucional - ação popular, ação civil pública, mandado de injunção etc. - tornase um instrumento privilegiado de participação política e exercício permanente da cidadania" (GUERRA FILHO, 2001, p. 26).

É de se reconhecer que "os processos coletivos são palco de conflitos internos da sociedade, relacionados, por vezes, com políticas públicas e com relevantes questões econômicas e, em certos casos, com complexidade científica" (MENDES, 2007, p. 19). Contudo, é exatamente por essas peculiaridades e pela importância do interesse em questão, que o processo coletivo deve receber uma atenção diferenciada.

Ricardo de Barros Leonel (2002) identifica a importância do processo coletivo ao considerar os resultados dele decorrentes. Nas palavras do autor, "a importância do processo está no alcance de seus resultados, vale afirmar, que sua utilidade é medida justamente na razão direta dos benefícios que possa trazer para o detentor de um interesse juridicamente protegido no ordenamento material" (LEONEL, 2002, p. 21-23). E continua: “é a visão do processo coletivo como instrumento de integração democrática, participativa, de cunho técnico-jurídico e político".

Por mais que as regras do Processo Civil ainda em vigor não se coadunem com a realidade da tutela transindividual, deve-se buscar dentro do processo coletivo formas para a máxima proteção dos interesses em questão. O exercício jurisdicional na seara coletiva deve se sobrepor às regras dos conflitos interindividuais, e utilizar-se de interpretações e recursos voltados à melhor guarda dos interesses da coletividade. Seguindo o entendimento de Paulo de Tarso Brandão (2008, p. 109):

[...] a função jurisdicional pelo Poder Judiciário é fundamental para a efetividade do Direito na forma de tratamento de conflitos. É possível dizer-se, também, que, para que isso aconteça não pode o Poder Judiciário continuar a operar com conceitos e instrumentos processuais que já não correspondam aos âmbitos conflituais de momentos passados e, ainda, deve incorporar os conceitos e instrumentos processuais 
decorrentes de novas formas de conflitos, típicos da dinamicidade dos interesses da Sociedade.

Mister o reconhecimento de que a jurisdição na seara coletiva requer um processo com características próprias, guiado justamente pelo pensamento de que se trata de um recurso destinado à defesa de interesses da sociedade. Deve se buscar, então, ultrapassar as barreiras criadas pelas legislação processual atual, a fim de proporcionar um processo coletivo que possibilite a máxima efetividade no amparo dos anseios, carências e interesses da coletividade.

\section{O JUIZ}

O Juiz, nas demandas coletivas, deve ser visto como agente do Estado vocacionado à garantia dos direitos da sociedade. Existindo na localidade competência própria ou não para os processos coletivos, cabe ao Juiz (e aos respectivos Tribunais) um maior cuidado com este tipo de demanda.

Exatamente porque o processo coletivo trata de questões da sociedade, e sendo o Estado um instrumento a serviço da Sociedade, é papel do Juiz proporcionar a máxima efetividade da tutela judicial nas demandas coletivas. Iniciada a lide, cabe ao Juiz conduzir o processo da forma que melhor resguarde os interesses da coletividade. O Juiz deve se pautar pela importância do bem jurídico tutelado.

É necessário ter em mente a importância da tutela coletiva como instrumento da sociedade para resguardar os seus direitos, e o Juiz deve perceber que a evolução da sociedade requer uma nova postura do judiciário. Como diz Paulo de Tarso Brandão (2008, p. 313), "sendo o Estado um instrumento a serviço da Sociedade, as demandas desta se modificam e se ampliam, determinando novos compromissos e novos comprometimentos por parte daquele."

Ademais, é essencial reconhecer que as demandas coletivas, oriundas especialmente dos novos "nichos" de conflituosidade da sociedade moderna (ou pós-moderna) exigem um tratamento diferenciado e soluções que tragam benefícios efetivos para a sociedade. Willis Santiago Guerra Fillho escreve:

[...] o que se deseja enfatizar aqui é a circunstância de que na pós-modernidade dá-se uma pluralidade de descrições da realidade social igualmente válidas. Em decorrência disso, também as prescrições feitas a partir de tais descrições são plúrimas. O ideal, então, é tentar combiná-las, a fim de obtermos soluções mais adequadas, porque mais abrangentes, para problemas sociais (GUERRA FILHO, 2001, p. 24). 
A partir do momento em que questões que envolvem importantes interesses da sociedade chegam ao Judiciário, é papel do Juiz (como agente do Estado) zelar para que o direito da coletividade seja garantido. O cidadão não está interessado em regras de legitimidade ou de alcance da sentença, mas sim de que seus interesses como membro da sociedade sejam preservados.

O magistrado não deve se utilizar de regras processuais para se esquivar de conhecer e decidir as causas que envolvem tais direitos. Até porque o Poder Judiciário aparece como um grande instrumento democrático na solução dos litígios que envolvem as coletividades. Seguindo ensinamento de Lênio Luiz Streck $(2009$, p. 52) "inércias do Executivo e a falta de atuação do Legislativo passam a poder ser supridas pelo Judiciário, justamente mediante a utilização dos mecanismos jurídicos previstos na Constituição que estabeleceu o Estado Democrático de Direito."

O foco de tensão dos conflitos sociais volta-se para o Judiciário, que possui o poder/ dever de dirimir os conflitos que lhe são apresentados. Cabe, então, ao Juiz, o reconhecimento de seu papel como agente transformador da sociedade. Paulo de Tarso Brandão (2008, p. 311) leciona: "é exatamente por isso e para garantir não só o Direito como o próprio Estado Democrático de Direito, que deve o Poder Judiciário cumprir sua missão maior e interferir na implementação de políticas públicas."

Ainda que os processos coletivos tratem de assuntos complexos e envolvam grandes corporações e órgãos públicos, o Juiz deve conduzir e decidir a causa balizado no interesse em questão, interesse este que pode representar em proveito de uma coletividade determinável ou não, para esta e futuras gerações.

\section{AS PARTES}

Uma das grandes diferenciações da tutela coletiva diz respeito à legitimidade. A natureza do direito tutelado exige uma legitimação diferenciada para agir, já que não pertence a uma pessoa individualmente. Ainda que possam ser determinados os seus beneficiários, o interesse posto em juízo envolve uma coletividade, e sua tutela será mais eficaz na medida em que for tratada como interesse de um grupo.

Isso porque, como bem diagnosticam Mauro Cappelletti e Bryant Garth (1988, p. 26), os interesses da tutela coletiva: 
São interesses fragmentados ou coletivos, tais como o direito ao ambiente saudável, ou à proteção do consumidor. $\mathrm{O}$ problema básico que eles apresentam - a razão de sua natureza difusa - é que, ou ninguém tem direito a corrigir a lesão a um interesse coletivo, ou o prêmio para qualquer indivíduo buscar essa correção é pequeno demais para induzi-lo a tentar uma ação.

Ademais, diferente do processo ordinário, em que uma parte pleiteia em juízo um direito que lhe pertence, no processo coletivo são os interesses de uma coletividade que estão em debate, e exigem uma defesa especializada. Hugo Nigro Mazzilli (2005, p. 49) esclarece:

\begin{abstract}
Enquanto, nos conflitos individuais, aquele que pede a prestação jurisdicional é, de regra, quem invoca a titularidade do direito a ser defendido, já nos conflitos coletivos, o autor da ação civil pública ou coletiva defende mais do que o direito próprio à reintegração da situação jurídica violada, pois também e especialmente está a defender interesses individuais alheios, não raro até mesmo divisíveis, os quais são compartilhados por grupo, classe ou categoria de pessoas.
\end{abstract}

Desta feita, o que determina a legitimação na tutela coletiva é a importância e a abrangência do direito tutelado. Considerando que um grupo de pessoas, determinável ou não, será atingido pela decisão judicial, e que tal decisão afetará área significativa da esfera jurídica do cidadão (seja na área consumerista, ambiental, política, etc.), na tutela coletiva, é mister a definição de representantes com capacidade para a melhor defesa do direito em juízo.

Some-se a isso que os reais titulares do direito não ingressarão na lide, ainda que possam ser por ela atingidos. Diferentemente do litisconsórcio, em que duas ou mais pessoas atuam em determinado pólo, defendendo interesses próprios, na tutela coletiva o direito em litígio pertencerá a uma coletividade (determinável ou não) que não participará pessoalmente no processo. É inviável e/ou não recomendável que todos os interessados por um direito transindividual ingressem em juízo, seja para evitar o grande número de processos daí decorrente, seja para evitar decisões contraditórias.

Por esta razão, a legislação brasileira elenca determinados representantes com legitimidade diferenciada, justamente para demandar em juízo a favor dos interesses da coletividade. Tal situação é facilmente percebida, por exemplo, pela simples leitura do inciso LXX do art. $5^{\circ}$ da CF/88. Partido político com representação no Congresso Nacional, organização sindical, entidade de classe ou associação não vão litigar por interesses próprios, mas sim por direitos que dizem respeito à uma pluralidade de pessoas, relacionadas por situações de fato ou de direito. 
Também o artigo $4^{\circ}$ da Lei 7.347/85 (Lei da Ação Civil Pública) deixa claro a eleição de alguns entes capazes para defender judicialmente os direitos da coletividade. Como bem observa Ricardo de Barros Leonel (2002, p. 156), a legitimação para a demanda coletiva afasta-se dos resquícios da concepção tradicional. No processo coletivo não há um interesse direto entre o representante e o objeto da demanda, e a solução da demanda não se limita ao círculo de interesses da pessoa que litiga em juízo.

Nas demandas coletivas há que se falar em um representante adequado, que esteja apto a patrocinar os interesses da coletividade em juízo. Como bem salienta Ada Pellegrini Grinover, Aluísio Gonçalves de Castro Mendes e Kazuo Watanabe (2007, p. xx):

Esse instituto (do representante adequado), desconhecido no processo individual, alicerça no processo coletivo a legitimação, exigindo que o portador em juízo do interesses ou direitos difusos, coletivos e individuais homogêneos apresente as necessárias condições de seriedade e idoneidade, até porque o legitimado é o sujeito do contraditório, do qual não participam diretamente os membros do grupo, categoria ou classe de pessoas. Embora a legislação atual brasileira não mencione expressamente a representatividade adequada, ela inquestionavelmente pode ser vislumbrada em normas que dizem respeito à legitimação das associações.

O legitimado deve possuir conhecimento e condições de postular e instruir o processo de forma a extrair do judiciário a máxima efetividade na tutela dos interesses coletivos postos em jogo. Considerando que os reais titulares do direito não farão parte do processo, cabe ao representante adequado a responsabilidade de melhor representar tais interesses.

Tal fenômeno também é percebido por Mauro Cappelletti e Bryant Garth (1988, p. 50):

Uma vez que nem todos os titulares de um direito difuso podem comparecer a juízo por exemplo, todos os interessados na manutenção da qualidade do ar, numa determinada região - é preciso que haja um 'representante adequado' para agir em benefício da coletividade, mesmo que os membros dela não sejam 'citados' individualmente.

Ricardo de Barros Leonel (2002, p. 173) arremata:

Assim, a adequação da representação assegura: a efetiva defesa dos interesses metaindividuais em juízo; a perfeita proteção das posições jurídicas dos lesados que integram a classe mas estão ausentes; o cumprimento das garantias constitucionais do processo; 'legitima' o processo coletivo e seus institutos como forma econômica de equacionamento de conflitos; 'legitima' a extensão subjetiva dos efeitos do julgado a quem não foi parte em sentido meramente formal. 
Reconhecida, então, a pertinência de que representantes adequados promovam o amparo dos direitos da coletividade, cabe a estes representantes, pessoas ou órgãos, a devida especialização teórica e técnica, bem como a busca por condições para a melhor postulação e instrução das demandas coletivas, resultando assim em uma tutela coletiva de qualidade, com respostas efetivas e importantes para a sociedade.

\section{ACESSO À JUSTIÇA}

O tema Acesso à Justiça é recorrente entre os juristas. Direito fundamental especialmente consagrado no artigo $5^{\circ}$, XXXV da Constituição da República ${ }^{7}$, resta a discussão acerca da efetividade e do alcance de tal dispositivo. Mauro Cappelletti e Bryant Garth (1988, p. 8) tratam do tema com a seguinte visão:

\footnotetext{
A expressão 'acesso à Justiça' é reconhecidamente de difícil definição, mas serve para determinar duas finalidades básicas do sistema jurídico - o sistema pelo qual as pessoas podem reivindicar seus direitos e/ou resolver seus litígios sob os auspícios do Estado. Primeiro, o sistema deve ser igualmente acessível a todos; segundo, ele deve produzir resultados que sejam individual e socialmente justos.
}

Partindo-se desta visão, temos, em apertada síntese, que a problemática do acesso à justiça pode ser inicialmente divida em duas frentes: a acessibilidade ao sistema, e à qualidade de suas decisões.

No tocante à acessibilidade, tem-se que sistema judiciário pátrio, como dito acima, deve ser igualmente acessível a todos, e o texto constitucional brasileiro não impõe nenhuma barreira ao Acesso à Justiça. Ao contrário, estabelece que nenhuma lesão ou ameaça a direito deixará de ser apreciada pelo Poder Judiciário.

Percebe-se então, que não devem existir empecilhos ao acesso ao Judiciário. Como bem observa Konrad Hesse (1998, p. 270) "a recorrência à via judicial não deve ser dificultada em uma forma não-exigível que não pode ser justificada por razões de fundo" [...] "garante também a efetividade da proteção jurídica no sentido de um direito a um controle judicial eficaz em todas as instâncias existentes."

O acesso ao Judiciário é direito fundamental de que a parte dispõe para a proteção de seus interesses. Neste sentido, Paulo Márcio Cruz (2007, p. 176). constata:

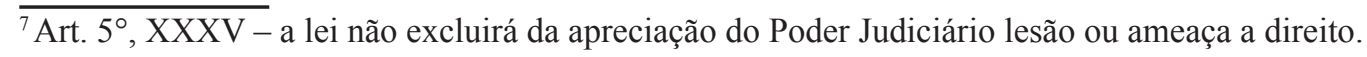


De fato, a proteção judicial encontra-se tão necessariamente ligada à existência de um direito, que se pode afirmar que um direito não existe se não há a correspondente possibilidade de ação perante um tribunal. Por esse motivo e como já foi destacado, o direito de acesso aos tribunais se autoconfigura como um direito fundamental, determinante quanto ao status de cidadão no Estado Democrático de Direito. Faz parte de toda a ordem constitucional democrática, atualmente, o direito de todo cidadão recorrer aos tribunais para defender seus direitos e interesses.

A existência de normas e/ou obstáculos que dificultem o Acesso à Justiça estão manifestamente em desacordo com os novos ideais constituintes de 1988. Seguindo lição de Lenio Streck (2009, p. 257), "sendo o texto constitucional, em seu todo, dirigente e vinculativo, é imprescindível ter em conta o fato de que todas as normas infraconstitucionais, para terem validade, devem passar, necessariamente, pelo processo de contaminação constitucional.”

Contudo, mais que o simples acesso ao Judiciário, segue-se o ensinamento de Paulo de Tarso Brandão (2007) no sentido de que o cidadão tem direito a uma decisão sobre o mérito de sua demanda apresentada à Justiça. Para o referido autor, “o direito de ação [...] nada mais é do que a busca da decisão judicial sobre um conflito submetido ao Estado, devedor do pronunciamento sobre ele, em virtude da vedação da autotutela". E acrescenta:

O conhecimento do conflito pelo órgão encarregado da prestação jurisdicional consiste numa garantia fundamental. Na outra face, é direito fundamental o acesso ao Poder Judiciário para buscar a decisão de qualquer conflito, ainda que aquele que busque tal decisão não tenha qualquer direito material ou esteja totalmente equivocado. A prestação jurisdicional requer decisão sobre o mérito do conflito. Sintetizando, a vedação constitucional de qualquer disposição legal - sem lei, então, seria mais grave - que pretenda afastar o Poder Judiciário do conhecimento de lesão ou ameaça a lesão a qualquer direito, constitui, a um só tempo, garantia e direito fundamental (BRANDÃO, 2007, p. 775-776).

Trazendo para a seara coletiva, tem-se que o Acesso à Justiça também assume feições próprias e diferenciadas. O Acesso à Justiça na tutela transindividual será efetivo pela ausência de obstáculos tanto para a proposição, como para o desenvolvimento do processo (seja pelos custos, seja pela dificuldade na produção de provas, seja por pressões políticas, etc.), até chegarse a uma decisão que não somente ponha fim à lide, mas sim que apresente uma solução para o problema social deduzido em juízo.

Ademais, considerando que no processo coletivo os verdadeiros titulares do direito em questão não ingressarão na lide, o Acesso à Justiça será tanto mais eficaz quanto maiores forem 
os canais que ligarem os cidadãos aos representantes adequados, e quanto maior for a atuação destes na defesa dos interesses da coletividade.

Inclusive, se pensarmos em legitimados com uma boa estrutura (teórica, financeira, sem vinculações político/partidárias, etc.) para patrocinar as lides ${ }^{8}$, e engajados no compromisso de amparo dos direitos da sociedade, ter-se-á um Acesso à Justiça sem que o cidadão tenha a necessidade de procurar auxílio, uma vez que sua esfera jurídica (seja consumerista, ambiental, etc.) estará resguardada pela atuação efetiva do representante adequado.

No que tange ao resultado da demanda, percebe-se que, como já visto, o objeto do processo coletivo será um direito coletivo em sentido amplo, que pode ser traduzido por um problema ou uma situação ilegal que atinge direta ou indiretamente um grupo determinável ou indeterminável de pessoas.

Desta feita, a decisão do processo não versará sobre um interesse direto da parte, mas sim sobre direitos que afetam uma coletividade. Assim, a importância do bem jurídico tutelado legitima que a condução do processo, bem com a posterior sentença se voltem à resolver o problema social posto em questão.

A constatação de que a decisão de uma ação coletiva afetará a esfera jurídica de uma coletividade de pessoas (determinável ou não), deve ser o norte para que tais processos recebam tratamento diferenciado, e que as decisões ali exaradas promovam o efetivo Acesso à Justiça daqueles que serão os realmente atingidos.

Afora isso, o Acesso à Justiça está umbilicalmente ligado à decisões socialmente justas. Clémerson Merlin Cléve, citado por Paulo de Tarso Brandão escreve (2007, p. 764): "não basta haver Judiciário; é necessário haver Judiciário que decida. Não basta haver decisão judicial; é necessário haver decisão judicial justa. Não basta haver decisão judicial justa; é necessário que o povo tenha acesso à decisão judicial justa."

E Horácio Wanderlei Rodrigues (1994, p. 29), citando Kazuo Watanabe conclui: “a problemática do acesso à Justiça não pode ser estudada nos acanhados limites do acesso aos órgãos judiciais já existentes. Não se trata apenas de possibilitar o acesso à Justiça enquanto instituição estatal, e sim viabilizar o acesso à ordem jurídica justa.”

Assim, o resultado socialmente justo será aquele que melhor resguardar os interesses da coletividade deduzidos em juízo. Não há se falar em efetivo Acesso à Justiça com decisões que se esquivem ou que não resguardem os interesses da sociedade.

\footnotetext{
${ }^{8}$ Destaca-se aqui a atuação do Ministério Público do Estado de Santa Catarina. Com suas procuradorias especializadas e a atuação efetiva de seus promotores, políticas públicas e assuntos importantes da sociedade catarinense tem a devida atenção e proteção. Para acompanhar: www.mp.sc.gov.br.
} 
As decisões judiciais dos processos coletivos deverão preocupar-se com o resultado prático da demanda e resolver o mérito da lide no sentido de por fim a um problema que atinge uma parte da sociedade (ou toda ela). Somente assim o Acesso à Justiça será concreto, com a solução litígio e sem a necessidade de novas e desnecessárias demandas.

\section{A TUTELA COLETIVA COMO INSTRUMENTO DE ACESSO À JUSTIÇA}

Considerando o que já foi visto, percebe-se que na seara coletiva a jurisdição recebe novas roupagens. Os quatro elementos que compõem a jurisdição (litígio, processo, juiz e partes) devem ser percebidos de forma diferenciada na tutela dos interesses da coletividade. Até o conceito e o alcance do Acesso à Justiça é distinto no processo coletivo.

O que se quer demonstrar com isso, é que as ações coletivas se constituem em uma importante ferramenta para a preservação e garantia dos direitos que afetam a esfera transindividual do cidadão. Ainda que este cidadão não procure a jurisdição, a atuação de seus representantes garantirá o devido amparo da esfera jurídica que está ao seu redor.

Para tanto, é necessário ter em mente as vantagens do processo coletivo, a fim de que a comunidade jurídica dê o devido valor a este tipo de demanda, encarando-a como uma importante forma de tutela dos direitos da sociedade. Ricardo de Barros Leonel (2002, p. 21-22). defende o processo coletivo como um "instrumento destinado a tornar acessível a justiça para aquelas situações em que ocorram ameaças ou lesões a interesses e direitos que pelos métodos tradicionais do processo de cunho clássico ou individual não seriam tuteláveis."

Ademais, esta categoria de direitos que extrapolam a individualidade do cidadão será melhor tutelada quanto mais coletivamente for considerada. Hugo Nigro Mazzilli (2005, p. 60) leciona:

\footnotetext{
Em matéria de lesão a interesses de grupos, classes ou categorias de pessoas, seria impraticável buscar a reparação da ordem jurídica violada se tivéssemos de sempre nos valer da legitimação ordinária, e, com isso, deixar a cada pessoa lesada a iniciativa de comparecer individualmente em juízo, diante dos ônus que isso representa, não só aqueles relacionados com o custeio da ação, como àqueles de caráter probatório. A necessidade de comparecimento individual à Justiça, sobre impraticável quando de lesões idênticas a milhares ou milhões de pessoas, produziria ainda dois efeitos indesejáveis: a) os poucos que se aventurassem a comparecer em juízo receberiam inevitáveis decisões contraditórias, o que, sobre injusto, ainda seria grave descrédito para o funcionamento do sistema; b) a grande maioria dos lesados acabaria desistindo da defesa de seus direitos, o que consistiria em verdadeira denegação de acesso à jurisdição para o grupo.
} 
Até porque, dentro do processo civil ordinário, com institutos nitidamente voltados para a solução de demandas interindividuais, a busca por direitos coletivos esbarraria em uma série de regras e procedimentos que, ou inviabilizaria, ou esvaziaria o conteúdo do litígio. Mauro Cappelletti e Bryant Garth (1988, p. 49-50) bem visualizam esta situação:

\begin{abstract}
A concepção tradicional do processo civil não deixava espaço para a proteção dos direitos difusos. O processo era visto apenas como um assunto entre duas partes, que se destinava à solução de uma controvérsia entre essas mesmas partes a respeito de seus próprios interesses individuais. Direitos que pertencessem a um grupo, ao público em geral ou a um segmento do público não se enquadravam bem nesse esquema. As regras determinantes da legitimidade, as normas de procedimento e a atuação dos juízes não eram destinadas a facilitar as demandas por interesses difusos intentadas por particulares.
\end{abstract}

Acrescente-se ao fato de que uma demanda coletiva bem conduzida tem o potencial de resolver de forma mais eficaz uma determinada situação que diversas demandas individuais sobre a mesma causa. A concentração de atos em um só processo, movido por um legitimado engajado com a defesa da sociedade e que possua a capacidade de postular e instruir devidamente a lide, leva a uma solução mais benéfica a sociedade. Hugo Nigro Mazzilli (2005, p. 48) constata esta situação:

Sob o aspecto processual, o que caracteriza os interesses transindividuais, ou de grupo, não é apenas, porém, o fato de serem compartilhados por diversos titulares individuais reunidos pela mesma relação jurídica ou fática, mas, mais do que isso, é a circunstância de que a ordem jurídica reconhece a necessidade de que o acesso individual dos lesados à Justiça seja substituído por um processo coletivo, que não apenas deve ser apto a evitar decisões contraditórias como ainda deve conduzir a uma solução mais eficiente da lide, porque o processo coletivo é exercido de uma só vez, em proveito de todo o grupo lesado.

Não se pretende aqui pregar o fim do processo individual, até porque demandas entre partes sempre existirão, e novos direitos também surgem na seara individual, com a devida tutela do processo civil ordinário. O que se propõe é uma maior efetividade na utilização das ações coletivas como forma de Acesso à Justiça e proteção de interesses sociais, que afetam direitos que extrapolam a individualidade do cidadão. 
As relações de consumo e a guarda do meio ambiente são exemplos claros de direitos que necessitam de uma tutela diferenciada. Ações individuais sobre os referidos temas não trarão uma solução positiva para a sociedade. O reconhecimento de que estes novos "nichos" de conflituosidade requerem um tratamento coletivo, com decisões favoráveis à sociedade é sinônimo de Acesso à Justiça.

O resultado do processo acabará por atender uma função social, trazendo uma solução para a coletividade e resguardando interesses de pessoas que sequer participaram do processo. Utilizando-se ainda das palavras de Hugo Nigro Mazzilli (2005, p. 58) a "defesa judicial de interesses transindividuais de origem comum tem peculiaridades: não só esses interesses são intrinsicamente transindividuais, como também sua defesa judicial deve ser coletiva, seja em benefício dos lesados, seja ainda em proveito da ordem jurídica."

Paulo de Tarso Brandão bem diagnostica esta evolução da sociedade, e propõe que os direitos difusos e coletivos sejam tratados por uma teoria própria, voltada para a melhor defesa de tais interesses. Em suas palavras:

O desenvolvimento tecnológico e eletrônico e o superdimensionamento do Estado iniciados ainda no Estado Moderno, mas que se consolidam e se manifestam mais intensamente no Estado Contemporâneo, terminam por estabelecer uma conflituosidade potencial e abrangente, que vem causar um 'desequilíbrio conceitual na própria teoria geral do direito' [...] o desequilíbrio conceitual ocorrente no âmbito da teoria geral do direito, com o afloramento e crescimento dos interesses e direitos difusos e coletivos, não é somente uma modificação nos esquemas conceituais, mas corresponde a uma outra concepção sobre os instrumentos destinados à tutela de tais interesses (BRANDÃO, 2006, p. 141-142).

Lenio Luiz Streck (2009) conclui que sociedade atual necessita uma atuação jurídica distinta no que se refere aos direitos da coletividade. Considera que "o crescimento dos direitos transindividuais e a crescente complexidade social (re)clamam novas posturas dos operadores jurídicos" (STRECK, 2009, p. 17). No mesmo sentido, Ada Pellegrini Grinover, Aluísio Gonçalves de Castro Mendes e Kazuo Watanabe (2007) percebe a necessidade de um repensar a processualística brasileira, dando-se maior ênfase à tutela das ações coletivas. Em suas palavras:

A análise dos princípios gerais do direito processual, aplicados aos processos coletivos, demonstrou a feição própria e diversa que eles assumem, autorizando a afirmação 
de que o processo coletivo adapta os princípios gerais às suas particularidades. Mais vistosa ainda é a diferença entre os institutos fundamentais do processo coletivo em comparação com os do individual (GRINOVER, MENDES; WATANABE , 2007, p. $15)$.

Constata ainda Ada Pellegrini Grinover, Aluísio Gonçalves de Castro Mendes e Kazuo Watanabe (2007) que uma utilização eficaz da tutela coletiva tem o condão de promover o Acesso à Justiça de toda uma coletividade. Para esta autora, "o acesso à justiça para a tutela de interesses transindividuais, visando a solução de conflitos que, por serem de massa, têm dimensão social e política, assume feição própria e peculiar no processo coletivo.” E conclui assim:

O princípio que, no processo individual, diz respeito exclusivamente ao cidadão, objetivando nortear a solução de controvérsias limitadas ao círculo de interesses da pessoa, no processo coletivo transmuda-se em princípio de interesse de uma coletividade, formada por centenas, milhares e às vezes milhões de pessoas (GRINOVER, MENDES; WATANABE, 2007, p. 12).

Percebe-se então que a tutela coletiva pode servir de instrumento para a concretização do Acesso à Justiça. Diferentemente do processo individual, a atuação dos legitimados em prol da sociedade resguardará direitos dos cidadãos, sem que estes tenham a necessidade de procurar o Judiciário, trazendo benefícios para a sociedade.

E os resguardará numa tutela mais eficiente, em um processo garantidor de direitos, movido por um legitimado capacitado e engajado para a defesa dos interesses coletivos, e julgado por um Juiz comprometido com a efetivação dos princípios Estado Democrático, que agirá em benefício desta e de futuras gerações.

\section{CONCLUSÃO}

O presente artigo pretendeu demonstrar que a Tutela Coletiva pode ser um importante instrumento para a concretização do direito de Acesso à Justiça. A partir do reconhecimento de direitos que extrapolam a esfera individual do cidadão, faz-se necessário uma ferramenta que possa garantir estes interesses em benefício dos próprios cidadãos e da sociedade. 
Procurou-se apresentar a Tutela Coletiva como um exercício diferenciado de Jurisdição, com uma caracterização própria de seus elementos. Litígio, processo, juiz e partes devem ser reinterpretados para uma maior efetividade das demandas coletivas.

Ademais, percebeu-se que o próprio instituto do Acesso à Justiça recebe uma nova roupagem quando direcionado à tutela dos interesses da coletividade. Diferentemente do processo civil ordinário, no processo coletivo o Acesso à Justiça dá-se principalmente pela atuação de representantes adequados, que litigarão por direitos que atingem uma coletividade (determinável ou não) de pessoas, que não atuarão efetivamente nos processos.

Por fim, conclui-se reconhecendo a importância da Tutela Coletiva como instrumento de Acesso à Justiça. Demandas coletivas propostas por representantes engajados com os interesses da coletividade, mediante processos utilizados como ferramentas para a concretização de Direitos, e julgadas por Juízes comprometidos com os ideais do Estado Democrático de Direito, acabarão por concretizar o Acesso à Justiça de todos aqueles que se beneficiarão com tais decisões (não raras vezes em número indeterminável, como nas tutelas ambientais), promovendo o bem de toda a sociedade.

\section{REFERÊNCIAS}

ALCALÁ-ZAMORA Y CASTILHO, Niceto. Estudios de teoria general e historia del processo. México: Universidade Nacional Autônoma de México, 1974. Tomo I

BOBBIO, Norberto. A era dos direitos. Tradução de Carlos Nelson Coutinho. Rio de Janeiro: Elsevier, 2004. Título original: L'età dei Diritti.

BONAVIDES, Paulo. Curso de direito constitucional. 13. ed. São Paulo: Malheiros, 2003.

BRANDÃO, Paulo de Tarso. Ações constitucionais: novos direitos e acesso à justiça. 2. ed. Florianópolis: $\mathrm{OAB} / \mathrm{SC}, 2006$.

CAPPELLETTI, Mauro; GARTH, Bryant. Acesso à justiça. Tradução de Ellen Gracie Northfleet. Porto Alegre: Sérgio Fabris, 1988.

CRUZ, Paulo Márcio. Fundamentos do direito constitucional. 2. ed. Curitiba: Juruá, 2007.

GRINOVER, Ada Pellegrini; MENDES, Aluísio Gonçalves de Castro; WATANABE, Kazuo (Coord.). Direito processual coletivo e o anteprojeto de código brasileiro de processos coletivos. São Paulo: Revista dos Tribunais, 2007. 
GUERRA FILHO, Willis Santiago. Processo constitucional e direitos fundamentais. 2. ed. São Paulo: Celso Bastos, 2001.

HESSE, Konrad. Elementos de direito constitucional da república federal da Alemanha. Porto Alegre: Sérgio Fabris, 1998.

LEONEL, Ricardo de Barros. Manual do processo coletivo. São Paulo: Revista dos Tribunais, 2002.

MAZZILLI, Hugo Nigro. A defesa dos interesses difusos em juízo: meio ambiente, consumidor, patrimônio cultural, patrimônio público e outros interesses. 18. ed. São Paulo: Saraiva, 2005.

MEDINA, José Miguel Garcia (2007)

MENDES (2007, p. 19).Falta

OLIVEIRA NETO, Francisco José Rodrigues de; COUTINHO, Jacinto Nelson de Miranda;

MEZZAROBA, Orides; BRANDÃO, Paulo de Tarso (Org.). Constituição e estado social: os obstáculos à concretização da Constituição. São Paulo: Revista dos Tribunais: Coimbra, 2008.

PASOLD, Cesar Luiz. Prática da pesquisa jurídica e metodologia da pesquisa jurídica. 10. ed. Florianópolis: $\mathrm{OAB} / \mathrm{SC}, 2007$.

RODRIGUES, Horácio Wanderlei. Acesso à justiça no direito processual brasileiro. São Paulo: Acadêmica, 1994.

STRECK, Lenio Luiz. Hermenêutica jurídica e(m) crise: uma exploração hermenêutica da construção do direito. 8. ed. Porto Alegre: Livraria do Advogado, 2009.

RECEBIDO: 29/10/2010

APROVADO: 03/12/2010 